\title{
RESILIENSI PADA MAHASISWI BERCADAR DI KOTA SEMARANG
}

\author{
Efrika Ayu Vegawati dan Titin Suprihatin \\ Fakultas Psikologi Universitas Islam Sultan Agung, Jl Kaligawe Raya km 4, Semarang \\ Email: titin@unissula.ac.id
}

\begin{abstract}
Abstrak
Penelitian ini bertujuan untuk mengetahui dan memahami gambaran resiliensi berdasarkan karakteristik resiliensi serta faktor-faktor yang mempengaruhi resiliensi pada mahasiswi bercadar di kota Semarang. Penelitian ini menggunakan pendekatan kualitatif dengan jenis penelitian fenomenologi. Subjek terdiri dari tiga mahasiswi bercadar yang berkuliah di perguruan tinggi negeri kota Semarang. Subjek dipilih berdasarkan teknik purposive sampling. Metode pengumpulan data menggunakan wawancara secara mendalam dan observasi. Hasil penelitian menunjukkan bahwa gambaran resiliensi subjek diperoleh dari lima karakteristik resiliensi yaitu perseverance, equaminity, meaningfulness, self reliance dan existential alones. Faktor-faktor yang berpengaruh pada resiliensi subjek yaitu karakteristik individu, pengaruh keluarga, lingkungan sekitar dan kelembagaan. Terdapat perbedaan tingkat kemampuan resiliensi dari diri ketiga subjek yang digambarkan subjek AM lebih dominan perseverance, subjek DN lebih dominan meaningfulness dan subjek SD lebih dominan self reliance. Akan tetapi, ketiga subjek memiliki kesamaan dalam hal faktor yang berpengaruh pada kemampuan resiliensi yaitu karakteristik individu tanpa ada pengaruh dari orang tua, lingkungan sekitar dan kelembagaan atau pihak universitas yang justru masih memberikan penilaian negatif, bahkan penolakan kepada keberadaan perempuan bercadar.
\end{abstract}

Kata kunci: mahasiwi bercadar; resiliensi

\section{RESILIENCE OF VEILED STUDENTS IN SEMARANG CITY}

\begin{abstract}
This study aims to know and understand description of the resilience based on characteristics resilience and the influence factors of resilience on a veiled students in the city of Semarang. This study using a qualitative approach with phenomenology research. Subjects consited of three veiled students who studying at universities of Semarang city. Subject selected by purposive sampling technique. Methods of data collection using in-depth interviews and observation. The results showed that the description of the resilience on subjects is obtained from the resiliensi five characteristics that is perseverance, equaminity, meaningfulness, self reliance and existential alones. The influence of factors resilience on subjects that is individual characteristics, the influence of the family, environment and institutional.There is a difference in ability of resilience between third subject descpripted AM more dominant perseverance, the subject $D N$ more dominant meaningfulness and the subject SD more dominant self reliance. However, the three subjects have in equation factors that affect of the ability of resilience is characteristic individuals without any support from the parents, the neighborhood and institutional or university who still provide negative ratings, even a refusal to the presence of veiled women.
\end{abstract}

Keyword: resilience; veiled students 


\section{Pendahuluan}

Manusia diciptakan sebagai makhluk religius yang dimaksud dalam hal ini yaitu memiliki kecenderungan untuk mengikuti dan patuh terhadap perintah Tuhan. Berbicara mengenai mahluk religius maka tidak terlepas dari pembahasan sebuah agama. Indonesia merupakan negara yang berpenduduk mayoritas beragama Islam (Iskandar, 2013). Islam sendiri merupakan suatu agama ramhatan lil 'alamin yang diperintahkan oleh Allah yaitu orang mukmin dilarang untuk berlaku sewenang-wenang terhadap makhluk Allah lainnya. Sebagai bukti, diriwayatkan dari Rasullah yang sangat memuliakan kaum hawa atau wanita. Bentuk memuliakan seorang wanita dari Rasulullah yaitu adanya anggapan bahwa surga ada di telapak kaki seorang lbu yang merupakan seorang wanita (Azzahra, 2016). Hal ini yang menjadikan muslimah selalu diidentikkan sebagai perhiasan di dunia. Muslimah sendiri telah diperintahkan oleh Allah agar dapat menjaga kemuliaannya. Kemuliaan muslimah dalam hal ini yaitu menjaga aurat agar terhindar dari pandangan orang-orang yang bukan muhrimnya yang dapat menimbulkan fitnah (Shihab, 2004).

Setiap muslimah yang telah memasuki usia baligh, maka diwajibkan untuk menutup aurat dengan sempurna sesuai dengan syariat Islam (Iskandar, 2013). Perintah menutup aurat telah tertulis dalam QS. An-Nur 31 yang memerintahkan seorang muslimah harus mampu menjaga pandangan, kemaluan dan auratnya dengan kain kerudung ke dadanya dan QS. Al-Ahzab 59 yang memerintahkan seorang muslimah harus mampu menutup jilbabnya keseluruh tubuh agar mudah dikenali sebagai orang mukmin. Jika melihat terjemahan QS. Al-Ahzab 59, maka muslimah diperintahkan untuk menutup jilbab keseluruh tubuh. Hal ini yang dimaksud bukanlah jilbab hanya sekedar menutupi bagian kepala atau rambut saja. Muslimah hendaknya menggunakan jilbab yang menutup keseluruh tubuh, diantaranya menutup bagian dada dan bagian punggung atau hingga menutup telapak tangan dan bagian muka, sehingga yang terlihat hanya tinggal sebatas mata. Penggunaan jilbab ini sering disebut dengan cadar.

Cadar merupakan kain yang menutupi wajah seorang muslimah sehingga saat menggunakannya hanya mata saja yang terlihat. Penggunaan cadar ini juga dipadukan dengan muslimah yang biasanya menggunakan penutup pergelangan dan telapak tangan serta mengenakan baju terusan panjang atau yang sering disebut gamis. Muslimah bercadar juga biasanya cenderung menggunakan pakaian berwarna hitam atau berwarna gelap agar muslimah terhindar dari sifat berlebih-lebihan atau tabarruj yang nantinya dapat mengundang perhatian orang-orang yang bukan muhrimnya (Ratri, 2011).

Muslimah Indonesia yang menggunakan hijab tercatat sudah sebanyak 20 juta jiwa (Hadi, 2015). Hal ini tidak terlepas dari fenomena penggunaan cadar khususnya dikalangan muslimah kota Semarang yang menunjukkan jumlah masyarakat kota Semarang beragama Islam yaitu sebanyak 1.335.587 jiwa dengan total jumlah penduduk beragama sebanyak 1.595.267 jiwa (Badan Pusat Statistik, 2017). Hal ini berhubungan dengan penggunaan cadar merupakan lanjutan dari penggunaan hijab itu sendiri (Ratri, 2011). Pada kenyataannya muslimah yang menggunakan hijab lebar maupun cadar tidak diikuti dengan penerimaan yang baik di tengah masyarakat. Muslimah berhijab lebar maupun cadar masih sering dianggap sebagai seseorang yang kuno, kaku dan dipandang sebelah mata karena terkesan fanatik, Islam radikal, Islam garis keras atau bahkan diidentikan dengan teroris (Ratri, 2011). Pandangan masyarakat inilah yang kemudian membangun sebuah diskriminasi bagi wanita yang 
menggunakan cadar karena mereka dianggap berbeda dengan muslimah lain yang tidak bercadar (Ratri, 2011).

Awalnya, beberapa dari muslimah merasa sedih karena masih ada orang yang memandang diri mereka dengan pandangan negatif (Nawir, 2016), padahal semua yang dilakukan semata-mata merupakan bentuk ketaatan pada Allah bukan untuk merugikan orang disekitar. Hal ini sesuai dengan hasil wawancara singkat kepada dua orang mahasiswi bercadar berinisial AT dan P yang memilih tetap bercadar meski keluarga, teman, dan lingkungan disekitar masih banyak memberikan penilaian negatif terkait dengan cadar yang dugunakan. Dari wawancara tersebut diketahui bahwa muslimah bercadar berusaha menerima dengan ikhlas dan tetap tegar dalam menghapi cobaan dari Allah yang menyertai proses hijrah muslimah itu sendiri. Munculnya sumber masalah dan cobaan dalam hidup muslimah bercadar kemudian menjadikan diri muslimah sebagai pribadi yang tangguh. Ketangguhan untuk menghadapi masalah yang terkait dengan penampilan mereka yang berbeda dari kebanyakan muslimah lainnya. Pribadi tangguh tersebut dinamakan sebagai kemampuan resiliensi (Wijayanti, 2008).

Resiliensi merupakan suatu kemampuan yang dimiliki oleh seorang individu, dimana dirinya dapat mengambil makna positif dari setiap kejadian dalam hidup yang memberikan tekanan, sehingga mampu melanjutkan hidup dan menyelesaikan masalah dengan kesadaran intelektual yang sehat (Richardson, 2002). Apabila seseorang tidak memiliki resiliensi dalam dirinya maka akan mudah merasa gagal dan sulit untuk melanjutkan hidup. Seseorang juga akan merasa sulit untuk mengembangkan diri pada pengalaman baru serta sulit mengambil hikmah dari kegagalan yang pernah terjadi dalam hidup (Nasution M. , 2011). Hal ini berbeda dengan diri muslimah bercadar yang memiliki ketangguhan untuk tetap bercadar meski ada banyak penilaian negatif di tengah masyarakat.

Berdasarkan fenomena yang telah ditemukan melalui wawancara pendahuluan. Oleh karena itu, peneliti merasa tertarik untuk meneliti lebih dalam mengenai gambaran resiliensi dan faktor-faktor yang mempengaruhi resiliensi pada mahasiswi bercadar di kota Semarang.

\section{Landasan Teori}

\section{Resiliensi}

Resiliensi menurut Henderson dan Milstein (2003) merupakan kemampuan yang dimiliki oleh seorang manusia agar dapat bangkit dari keterpurukan, bahkan setelahnya dapat menjadi seseorang yang lebih kuat dalam menjalani permasalahan kehidupan (Henderson \& Milstein, 2003). Adapun menurut Schoon (2006) resiliensi didefinisikan sebagai proses yang dinamis dari seorang individu yang dapat beradaptasi dengan sumber masalah yang sedang dihadapi (Schoon, 2006).

Karakteristik resiliensi yang dimiliki oleh seorang individu, sesuai dengan pendapat Wagnild dan Young ada lima kriteria (Wagnild \& Young, 1993), yaitu: (a) Perseverance, kemampuan yang dimiliki oleh seseorang untuk menjadi pribadi yang penuh kegigihan agar dapat bertahan dan memperjuangkan hidup dalam menghadapi peristiwa yang terasa sulit, (b) Equaminity, pandangan yang ada dalam diri individu mengenai pengalaman kehidupan yang dianggap merugikan, namun individu tersebut memiliki kemampuan untuk lebih dapat melihat sisi positif dari setiap hal negatif yang terjadi didalam hidupnya, (c) Meaningfulness, suatu kesadaran dalam diri seorang individu bahwa dirinya memiliki tujuan hidup dan memerlukan sebuah usaha yang berguna untuk mewujudkan tujuan hidupnya tersebut, (d) Self Reliance, suatu keyakinan yang dimiliki oleh seorang individu berupa pemahaman mengenai kemampuan dan keterbatasan yang ada dalam dirinya, sehingga apabila akan 
melakukan sesuatu maka disertai dengan pertimbangan, (e) Existential Aloness, suatu kesadaran yang dimiliki seorang individu yang menganggap bahwa setiap orang merupakan individu yang unik, sehingga mampu mandiri dan menerima diri dengan apa adanya.

Adapun menurut Patilima faktor-faktor yang mempengaruhi resiliensi (Patilima, 2015), yaitu: (a) karakteristik dari individu yang dapat menjadi agen secara aktif yang dapat mengontrol diri serta lingkungannya. individu tersebut nantinya mampu meningkatkan resiliensi, sehingga dapat berinteraksi dengan masyarakat secara baik, (b) pengaruh keluarga yang merupakan sebuah kelompok yang memiliki peranan besar dalam mempengaruhi perkembangan seorang individu. keluarga juga terdiri dari para orang tua yang memliki pola pengasuhan terhadap seorang anak, (c) lingkungan sekitar yang merupakan sebuah tempat yang berpengaruh pada kehidupan seorang individu karena lingkungan merupakan suatu wadah yang pertama kali menanamkan nilai sosial. Lingkungan dapat memberikan pengaruh terhadap kemampuan resiliensi, yaitu ketika seorang individu mampu berinteraksi secara langsung dengan konteks sosial, (d) kelembagaan yang dapat dikaitkan dengan lingkungan kerja atau lingkungan sekolah seorang individu. Lembaga yang memiliki pengaruh pada perkembangan potensi seorang individu. Kemampuan resiliensi dapat dipengaruhi oleh faktor kelembagaan. Resiliensi dapat dibentuk jika didalamnya terjalin hubungan baik dan adaptasi yang positif antara individu dengan orang lain yang terkait dengan lembaga tersebut. Menurut Grothberg sumber yang dapat membentuk resiliensi terdiri dari tiga sumber (Grothberg H. , 1995), yaitu: (A) I Have, merupakan sumber pembentukan resiliensi yang asalnya dari luar, antara lain: a). Trusting Relationships, memiliki kepercayaan terhadap suatu hubungan dengan orang-orang terdekat yang dapat memberikan kasih sayang. b) Structure and rules at home, adanya struktur dan aturan didalam rumah oleh orang tua yang nantinya dalam menerapkan aturan tersebut diberlakukan adanya hukuman apabila individu tidak mematuhi aturan dan diberikan pujian apabila individu mematuhi aturan. c) Role models, orang yang memiliki peran sebagai informan mengenai hal-hal yang dapat dilakukan oleh seorang individu yang nantinya dapat ditiru oleh individu tersebut. d) Encouragement to be Autonomous, adanya usaha yang dapat dijadikan sebagai dorongan untuk seorang individu agar dirinya dapat menjadi seseorang yang mandiri. e) Access to Health, Education, Welfare, and Security Services, adanya kemudahan seorang individu untuk memperoleh akses pada bidang kesehatan, pendidikan, kesejahteraan dan pelayanan keamanan. (B) I Am, merupakan sumber pembentukan resiliensi yang asalnya dari kekuatan dalam diri individu, antara lain: a) Lovable and My Temperament is Appealing, dalam diri seorang individu pasti ada seseorang yang mampu mencintai dan menyukai sikapnya. Hal ini nantinya akan menjadikan individu tersebut bersikap baik terhadap orang yang memiliki rasa cinta dan suka pada dirinya, sehingga mampu mengatur sikap serta perilakunya jika sedang dihadapkan pada respon yang berbeda saat sedang berbicara bersama orang lain. b) Loving, Empathic, and Altruistic, apabila seorang individu memiliki seseorang yang mencintainya maka akan cenderung peduli terhadap orang lain sehingga individu tersebut akan berusaha menolong orang yang sedang menderita dan menggantinya dengan keadaan yang lebih baik. c) Proud Of Myself, seorang individu yangmemiliki perasaan bangga terhadap diri sendiri. d) Autonomous and Responsible, individu akan mampu melakukan hal-hal yang sesuai dengan keinginannya, namun tetap mengerti batasan sehingga dapat mengontrol dirinya. Selain itu, individu juga mampu menerima konsekuensi yang ditimbulkan dari perilakunya dengan tanggung jawab. f) Filled with Hope, Faith, and Trust, individu yang dalam dirinya selalu memiliki harapan, keyakinan, dan kepercayaan. (C) I Can, merupakan sumber pembentukan resiliensi yang asalnya dari kemampuan interpersonal yang dimiliki oleh individu dalam 
mengungkapkan perasaan maupun pikiran untuk berkomunikasi dengan orang lain, antara lain: a) Communicate, individu memiliki kemampuan untuk mengekspresikan pikiran serta perasaannya kepada orang lain dan mampu mendengarkan apa yang sedang dikatakan oleh orang lain serta mampu merasakan perasaan yang sedang dirasakan oleh orang lain. b) Problem solve, individu memiliki kemampuan untuk memecahkan masalah yang sedang dihadapi dalam kehidupannya. c) ManageMy Feelings and Impulses, individu memiliki kemampuan untuk mengenali perasaan dan emosinya sehingga mampu mengekspresikan kedalam bentuk kata-kata dan berbagai tingkah laku, namun tidak merugikan orang lain. Individu juga memiliki kemampuan untuk mengatur rangsangan yang ditimbulkan dari tindakan yang negatif. d) Gauge The Temperament Of Myself and Others, individu dapat memahami bagaimana temperamen diri sendiri (dalam hal bertingkah laku, merespon sebuah rangsangan, dan dalam mengambil sebuah resiko) dan juga mampu mengukur temperamen pada orang lain. Hal ini digunakan untuk mengetahui waktu yang diperlukan dalam berkomunikasi, membantu individu untuk mengetahui seberapa cepat reaksi apabila dihadapkan dengan respon dan mengetahui banyaknya individu yang dapat mencapai kesuksesan dalam berbagai macam situasi yang terjadi di kehidupannya. e) Gauge the temperament of myself and others, (Mencari Hubungan yang Dapat Dipercaya) individu dapat menemukan seseorang yang mampu dimintai pertolongan, saling berbagi perhatian yang nantinya akan dijadikan sebagai teman berdiskusi mengenai pemecahan masalah.

\section{Mahasiswi Bercadar}

Mahasiswi menurut UU Nomor 20 (2012) merupakan seseorang yang menjadi peserta didik dalam suatu perguruan tinggi (Undang-Undang Republik Indonesia Nomor 12 Tahun 2012 Tentang Pendidikan Tinggi, 2012). Sesuai dengan pernyataan yang dikemukakan oleh Engineer (2003, maka cadar atau niqab yaitu sebagai pakaian panjang yang tidak membentuk lekuk tubuh atau longgar yang menutupi kepala(Engineer, 2003). Sebagaimana yang juga dikemukakan oleh Shalih (2010)bahwa cadar dalam perspektif studi tafsir dalam agama Islam merupakan jilbab yang kainnya tidak menerawang atau tebal, longgar sehingga mampu menutup aurat wanita yang pemakaiannya termasuk dapat menutup wajah dan telapak tangan(Shalih, 2010).

Cadar menurut Taimiyah (2010)berarti an niqab atau cadar merupakan kain yang digunakan oleh wanita dengan cara diulurkan dari bagian atas kepala, sehingga tidak ada bagian wajah yang nampak kecuali kedua mata(Taimiyah, 2010). Seperti yang juga dikatakan oleh Sunesti (2012) bahwa cadar merupakan pakaian wanita yang menutup bagian wajah kecuali kedua mata (Sunesti, 2012). Tipe cadar menurut (Engineer, 1999), antara lain:

a. Cadar yang dipakai menggunakan selembar kain yang menutupi seluruh bagian kepala dan wajah, sehingga bagian yang terbuka hanyalah sepasang mata saja.

b. Cadar yang dipakai menggunakan kain yang menutupi sebagian kepala dan hidung dan membiarkan beberapa bagian dari wajah dan mata terbuka.

c. Cadar yang digunakan dengan kain yang menutupi seluruh bagian kepala dan bagian wajah dan hanya membiarkan satu mata saja antara salah satu mata sebelah kanan atau kiri yang terbuka. 


\section{Metode Penelitian}

Penelitian ini menggunakan pendekatan kualitatif dengan fenomenologi yang akan memaknai secara umum pengalaman hidup partisipan yang berterkaitan dengan fenomena atau masalah yang diteliti (Creswell J. W., 2015). Tujuan dari pendekatan fenomenologi untuk mengklarifikasikan fenomena yang sedang dialami oleh seseorang dalam hidupnya. Fenomenologi juga bertujuan untuk mendapatkan makna secara psikologis melalui fenomena yang dialami oleh partisipan dengan serangkaian analisis data.

Fokus penelitian ini yaitu gambaran resiliensi dan faktor-faktor yang mempengaruhi resiliensi pada mahasiswi bercadar di kota Semarang. Teknik pemilihan subjek yaitu dengan purposive sampling yang menggunakan beberapa kriteria yang disesuaikan oleh peneliti (Sugiyono, 2014). Subjek yang akan digunakan dalam penelitian kualitatif ini adalah individu yang memenuhi kriteria yaitu sebagai mahasiwi di perguruan tinggi negeri kota Semarang, bercadar minimal enam bulan dan bersedia untuk diwawancarai. Teknik pengambilan data yaitu dengan observasi dan wawancara secara mendalam untuk mendapatkan informasi dan data yang lengkap mengenai fenomena yang dialami oleh subjek penelitian yaitu mahasiwi bercadar. Wawancara dilakukan dengan menggunakan guideline interview yang disusun sebelum melakukan penelitian. Dalam penelitian ini, data yang akan mengetahui yaitu mengenai gambaran resiliensi menggunakan karakteristik resiliensi dan mengetahui faktor yang berpengaruh pada resiliensi.

Kriteria keabsahan data yaitu menggunakan triangulasi dan standar transferabilitas. Triangulasi merupakan suatu cara yang dilakukan dalam mengumpulkan data dengan menggabungkan beberapa sumber data yang didapat dari hasil wawancara, observasi dan dokumentasi. Standar transferabilitas merupakan suatu cara yang digunakan untuk mengetahui ketepatan hasil penelitian yang telah dilakukan. Transferabilitas dilakukan agar orang lain sebagai pembaca mampu memberikan pemahaman terhadap hasil penelitian, sehingga dapat diterapkan pada penelitian dimasa mendatang.

Teknik analisis yang digunakan dengan cara (a) mengorganisasikan data, (b) membaca dan membuat memo, (c) mendeskripsikan, mengklarifikasikan dan menafsirkan data menjadi kode dan tema, (d) menafsirkan data, (e) menyajikan dan memvisualisasikan data.

\section{Hasil dan Pembahasan}

Hasil penelitian menunjukkan bahwa gambaran resiliensi subjek 1 yang berinisial AM yaitu memiliki kegigihan (perseverance) yaitu tidak merasa tertekan, tidak merasa takut dan tidak mudah tersinggung ketika orang memberi tanggapan negatif. AM justru menjadikan hujatan sebagai sumber kekuatan untuk berjuang mempertahankan cadar yang digunakan. AM juga dapat mengambil sisi positif dari masalah yang terjadi (equaminity) yaitu dengan tetap berpikir positif ketika dipanggil "ninja" dan "maling" yang dianggap sebagai bentuk ketidaktakutan anak-anak kepada AM. AM seseorang yang sadar mengenai tujuan hidup (meaningfullnes) yaitu menjadikan cadar sebagai teman belajar untuk mencapai ridho Allah dan menganggap pertemuan dengan guru spiritual yang masih keturunan Rasul sebagai hal paling berharga dalam hidup. AM juga mampu melakukan pertimbangan sebelum melakukan suatu hal (self reliance) yang ditunjukkan dengan AM dapat membatasi interaksi dengan lawan jenis dan mengurangi aktivitas keluar kos saat malam hari. Meski AM tidak begitu dapat menyebutkan kekurangan dalam diri dikarenakan AM belum merasa menjadi seorang muslimah yang baik setelah bercadar. AM juga memiliki kesadaran bahwa setiap manusia merupakan individu yang unik, sehingga mampu mandiri (existential aloness) maka dari itu, AM sangat menghargai perbedaan 
pemahamaan dan pilihan hidup yang dimiliki oleh orang lain, sehingga AM tidak ingin berdebat untuk membenarkan pemahaman yang diyakini dengan orang lain. Faktor yang mempengaruhi resiliensi dalam diri AM juga berasal dari karakteristik individu AM sendiri. Hal ini dikarenakan AM yang mendapat pertentangan dari keluarga, sebagian teman dan masyarakat sekitar terkait dengan penggunaan cadar. Meski AM telah meminta ijin kepada kepala jurusan untuk bercadar saat dikampus, namun menurut AM peraturan universitas tidak sepenuhnya mendukung keinginan AM untuk bercadar.

Gambaran resiliensi subjek 2 yang berinisial DN yaitu memiliki kegigihan (perseverance) yaitu tergambar dari DN yang mempertahankan cadar karena ingin melindungi diri dari pandangan laki-laki yang bukan mahram. DN memiliki kemampuan dalam melihat sisi positif dari sebuah masalah (equaminity) yaitu tergambar dari pengalaman DN yang lebih memilih berpikir positif dengan terhadap tuduhan dan penolakkan dari para dosen sebagai wujud rasa kekhawatiran orang tua terhadap anak didiknya. DN memiliki tujuan hidup (meaningfullnes) yang menganggap cadar sebagai perjuangan agama dan tujuan dakwah yang dijadikan sebagai landasan saat menemui Allah dikehidupan akhirat yang lebih kekal, oleh karena itu DN tetap menggunakan cadar meski harus dipindahkan ke tempat PPL yang baru karena perintah dari dinas pendidikan yang disebabkan DN bercadar ketika mengikuti kegiatan PPL. DN juga selalu merasa segala ketetapan Allah memiliki tujuan tersendiri dalam hidup. DN juga dapat mengenali kekurangan yang ada dalam diri (self reliance) yaitu menganggap kepribadian introvert sebagai kekurangan, namun DN kurang percaya diri untuk menyebutkan kelebihan yang dimiliki. DN juga memiliki kesadaran bahwa setiap manusia merupakan individu yang unik, sehingga seseorang tersebut mampu mandiri dan menerima diri dengan apa adanya (existential aloness). Sesuai dengan DN yang merasa kagum dengan penampilan perempuan bercadar yang terlihat berbeda namun tetap terjaga. Meski DN juga memiliki penampilan yang berbeda, namun DN tetap dapat berinteraksi dengan teman satu kos. Faktor yang mempengaruhi DN memiliki resiliensi yaitu muncul dari karakteristik individu, meski DN mendapat ijin dari keluarga untuk bercadar, namun lebih dominan dari dalm diri DN sendiri. Hal ini dikarenakan DN yang masih mendapat pertentangan dari pihak dosen dan universitas serta lingkungan disekitar.

Gambaran resiliensi yang dimiliki oleh subjek 3 berinisial SD yaitu memiliki kegigihan dalam mempertahankan penggunaan cadar (perseverance) hanya sebatas karena merasa nyaman ketika bercadar, namun SD belum dapat memberanikan diri untuk bercadar ketika berada di lingkungan rumah dan universitas. Kemampuan SD dalam melihat sisi positif dari sebuah masalah (equaminity) yaitu ditunjukkan ketika SD tidak ingin meremehkan orang lain yang sempat memberikan penilaian negatif mengenai cadar. Hal ini dikarenakan SD menganggap orang lain tersebut belum mengerti mengenai hukum bercadar dalam agama Islam. SD juga sadar mengenai tujuan hidup (meaningfulness) yang ditunjukkan dengan menjalankan sunnah dan datang kesebuah kajian keagamaan merupakan hal yang berharga dalam hidup. SD juga menjadikan surga sebagai tujuan hidup, sehingga SD berusaha untuk memperbaiki diri salah satunya dengan belajar menggunakan cadar. SD juga dapat menyebutkan kemampuan yang dinilai sebagai kelebihan (self reliance). Kelebihan SD yaitu memiliki pendirian kuat, sedangkan kekurangan dalam diri SD yaitu boros dan cerewet. Setelah bercadar, SD juga sudah mulai dapat membatasi diri dari perilaku yang kurang baik, seperti mulai meninggalkan kebiasaan keluar malam ke tempat yang tidak baik dan mulai dapat menjaga diri saat berinteraksi dengan teman lawan jenis. Hal ini yang menjadi pertimbangan SD untuk bercadar. SD juga memiliki kesadaran dalam menerima perbedaan anggapan mengenai dari orang disekitar (existential aloness). 
SD menganggap perbedaan pendapat antara orang lain memang sudah menjadi bagian dari ketentuan Allah yang telah membuat umatnya sebagai umat yang berbeda-beda. Meskipun SD masih mendapatkan pertentangan karena perbedaan mengenai pemahaman menggunakan cadar, namun SD tetap dapat berinteraksi dengan orang disekitar. Faktor yang mempengaruhi resiliensi dalam diri SD berasal dari karakteristik individu. Hal ini dikarenakan keluarga SD yang memberikan penolakan keras berupa ancaman akan mengeluarkan SD dari rumah ketika SD tetap berusaha akan meggunakan cadar. Hal ini yang membuat SD tidak bercadar ketika di universitas karena SD merasa takut jika orang tua akan berurusan dengan pihak dosen, selain itu SD juga masih menerima pertentangan dari teman di universitas.

Berdasarkan hasil penelitian, maka diketahui bahwa ketiga subjek memiliki gambaran resiliensi yang berbeda satu sama lain. Gambaran resiliensi pada subjek 1 AM lebih dominan perseverance, subjek 2 DN lebih dominan meaningfulness dan subjek 3 SD lebih dominan self reliance. Ketiga subjek juga sama-sama memiliki faktor pembentuk resiliensi yaitu karakteristik individu. Hal ini dikarenakan selama ketiga masih menerima tanggapan negatif bahkan penolakan dari pihak keluarga, lingkungan sekitar dan kelembagaan.

\section{Kesimpulan}

Kesimpulan dalam penelitian ini adalah adanya kemampuan resiliensi dalam diri ketiga subjek yang digambarkan dengan karakteristik resiliensi yang berbeda satu sama lain. Subjek 1 lebih dominan perseverance, subjek 2 lebih dominan meaningfulness, subjek 3 lebih dominan self reliance. Faktor yang mempengaruhi resiliensi dalam diri ketiga subjek yaitu karakteristik individu.

\section{Kelemahan Penelitian}

Penelitian ini tentu memiliki kelemahan yaitu dalam melakukan observasi kurang mendalam. Peneliti kurang melakukan observasi saat subjek yang bercadar berinteraksi dengan orang disekitar. Peneliti hanya melakukan observasi saat akan diadakan wawancara dan saat berlangsungnya wawancara dengan memerhatikan intonasi dan mimik wajah subjek, Hal ini dikarenakan waktu yang kurang mendukung untuk melakukan observasi saat subjek berada di lingkungan kos atau rumah dan di lingkungan universitas.

\section{Saran}

Berdasarkan hasil penelitian yang telah dipaparkan di atas, peneliti memberikan beberapa saran, diantaranya:

1. Bagi subjek

Subjek 3 resiliensi yang lebih dominan yaitu self reliance, sebaiknya mampu untuk memberikan pengertian kepada orang tua terkait dengan penggunaan cadar. Hal ini dapat dengan cara mengajak orang tua untuk ikut dalam kajian keagamaan, memberikan buku mengenai hukum bercadar atau dengan bantuan seseorang yang dapat dijadikan perantara meyakinkan orang tua. Subjek 1 yang lebih dominan yaitu perseverance dan subjek DN lebih dominan yaitu meaningfulness, sebaiknya mampu mempertahankan perjuangan dalam menggunakan cadar untuk menjalankan sunnah Rasul dan berjuang dijalan dakwah.

2. Bagi peneliti selanjutnya 
Peneliti selanjutnya diharapakan mampu mengungkapkan variabel lain yang belum ada dalam penelitian ini dan memperdalam observasi saat subjek sedang menjalankan kegiatan yang melibatkan masyarakat.

\section{Daftar Pustaka}

Undang-Undang Republik Indonesia Nomor 12 Tahun 2012 Tentang Pendidikan Tinggi. (2012). Retrieved 4 6, 2017, from Portal Mahkamah Konstitusi: https://portal.mahkamahkonstitusi.go.id/eLaw/mg58ufsc89hrsg/1f32ffaa83555e001038d1e 0cda7b281849acef2d.pdf

AT. (2017, 2 11). Resiliensi pada mahasiswi bercadar di kota semarang. (E. A. Vegawati, Interviewer)

Azzahra, F. (2016, Mei 5). Islam memuliakan perempuan. Retrieved Maret 5, 2017, from VOAlslam: http://www.voa-islam.com/read/smart-teen/2016/05/05/43865/islam-memuliakanperempuan/

Badan Pusat Statistik. (2017). Jumlah pemeluk agama di kota Semarang, 2001 -2015. Retrieved 39 , 2017, from Badan Pusat Statistik kota Semarang: https://semarangkota.bps.go.id/linkTableDinamis/view/id/65

Banano, G. A., Renicke, C., \& Dekelv, S. (2005). Self enhancement among high exposure survivors of the September 11 terrorist Attack: resilience or social maladjusment. Journal Of Personality and Social Psychology. Vol 25, No. 6, 64-74.

Bungin, B. (2003). Analisis data penelitian kualitatif. Jakarta: PT Raja Grafindo Persada.

Coulson, R. (2006). Resilience and self-talk in. University Student: University of Calgary.

Creswell, J. W. (2015). Penelitian kualitataif \& desain risetn memilih di antara lima pendekatan. Yogyakarta: Pustaka Pelajar.

E, G. (1995). A guide to promoting resilience in children: strengthening the human spirit.

Engineer, A. A. (2003). Pembebasan perempuan. Yogyakarta: LKis Yogyakarta.

Giorgi, A., \& Giorgi, B. (2009). Fenomenologi. In J. A. Smith, Psikologi kualitatif panduan praktis metode riset (pp. 49-53). Yogyakarta: Pustaka Pelajar.

Grothberg, E. (1995). A guide to promoting resilience in children: strengthening the human spirit. the series early childhood development: practice and reflections. Number 8. The Hague: Benard van Leer Voundation.

Hadi, R. N. (2015, 4 14). Hijab, trend dan aturan. Retrieved 3 9, 2017, from Kompasiana: http://www.kompasiana.com/rizkinurismarinihadi/hijab-trend-danaturan_555476657397733a14905529

Henderson, N., \& Milstein, M. M. (2003). Resiliency in schools making it happen for students and educators. California, USA: Corwin Press, Inc.

Holaday, \& Phearson. (1997). Resilience and severe burns. Journal of counseling and development, 75,( 5), 346-356.

Ige, E. P. (2015). Insiden bule semarang dan wanita bercadar. Semarang: Liputan 6 Regional Semarang.

Iskandar, A. S. (2013). Konstruksi identitas muslimah bercadar. Artikel ilmiah hasil penelitian mahasiswa 2013, p. 2.

Maliani, Q. (2013). Hubungan antara religiusitas dengan resiliensi pada wanita muslimah bercadar usia dewasa awal di kota Bandung. Bandung: Jurusan Psikologi fakultas ilmu pendidikan Universitas Pendidikan Indonesia.

Mayasari, R. (2014). Mengembangkan pribadi yang tangguh melalui pengembangan pelatihan resiliensi. Jurnal dakwah, Vol. XV, No. 2 Tahun 2014, 267-269.

Nasution, M. (2011). Resiliensi daya pegas menghadapi trauma kehidupan. Medan: USU Press.

Nawir, M., \& Syarifudddin. (2016). Persepsi masyarakat tentang perempuan bercadar. Jurnal equilibirium FKIP Unismuh Makasar. Volume II No. 1 Januari 2016. 
P. (2017, 3 9). Resiliensi pada mahasiwi bercadar di kota Semarang. (E. A. Vegawati, Interviewer) Patilima, H. (2015). Resiliensi anak usia dini. Bandung: ALFABETA.

Poerwandari, E. K. (2007). Pendekatan kualitatif untuk penelitian perilaku manusia. Depok: Lembaga Pengembangan Sarana Pengukuran dan Pendidikan Psikologi (LPSP3 UI).

Putri, A. (2012). Pengaruh kelelahan emosional terhadap perilaku belajar pada mahasiswa yang bekerja. Jurnal ilmiah, 2.

Ratri, L. (2011). Cadar, media, dan identitas perempuan muslim. Vol 39, No.2 (2011), 32.

Reivich, K. (2002). The resilience factor 7 essensial skils for overcoming life's inevitable obstacles. New York, USA: Broadway Books.

Reivich, K., \& Shatte, A. (2002). The resilience factor 7 essential skils for overcoming life's inevitable obstacles. New York, USA: Broadway Books.

Rema, R. S. (2007). Perbedaan self-regulation pada mahasiswa yang bekerja dan mahasiswa yang tidak bekerja. Jurnal Universitas Paramadina .

Riandini, R. (2012). Niqab: jika belum sanggup, jangan mengejek!. Karanganyar, Jawa Tengah: VOA Islam.

Richardson, G. E. (2002). The metatheory of resilience and resiliency. Journal of clinical psychology, 58, 307-321.

Salim. (2002). Kamus bahasa Indonesia kontemporer. Jakarta: Modern English Press.

Sari, F. H., Lilik, S., \& Agustin, R. W. (2014). Studi fenomenologi mengenai penyesuaian diri pada wanita bercadar. Wacana Jurnal Psikologi VOL.6 NO.11 Januari 2014.

Schoon, I. (2006). Risk and resilience: adaption in changing times. Singapore: Cambridge University Press.

Shalih, A. U. (2010). Hukum cadar. Solo: At-Tibyan.

Shihab, M. Q. (2004). Jilbab: pakaian wanita muslimah (pandangan ulama masa lalu dan cendekiawan kontemporer). Jakarta: Lentera Hati.

Sugiyono. (2009). Metode penelitian kuantitatif dan kualitatif R\&D. Bandung: Alfabeta.

Sugiyono. (2014). Metode penelitian kuantitatif kualitatif dan R\&D. Bandung: Alfabeta.

Sunesti, y. (2012, April). Ruang publik dan ekspresi keberagaman perempuan berjilbab di Yogyakarta. SOSIOLOGI REFLEKTIF, Volume 6, Nomor 2, 11.

Taimiyah. (2010). Hijab dan cadar bagi wanita muslimah. Yogyakarta: At Tuqa.

VOA-islam.com. (2013). Kronologi dikeluarkan mahasiswi bercadar dari kampus STIKIM Jakarta. jakarta: VOA Islam.

Wagnild, G. M., \& Young, H. M. (1993). Development and psychometric evalution of the resilience scale. Journal of nursing measurement, 1, (2), 165-178.

Widuri, E. L. $(2012,8)$. Regulasi emosi dan resiliensi pada mahasiwa tahun pertama. humanitas, Vol. IX No.2 Agustus 2012, IX, 149.

Wijayanti, M. R. (2008). Gambaran resiliensi pada muslimah dewasa muda yang menggunakan cadar. Depok.

Yuniardi, M. S. (2009). Analisis potensi resiliensi korban lumpur panas lapindo: tinjauan pada tiap tahap perkembangan. Jurnal Psikologia, Volume 4, Nomor 2.

Yuniardi, M. S., \& Djudiyah. (2011). "Support group therapy" untuk mengembangkan potensi resiliensi remaja dari keluarga "single parrent" di kota Malang. Jurnal Psikobuana Vol.3, No.2, 135-140 